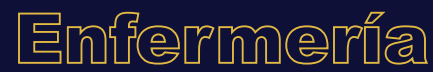

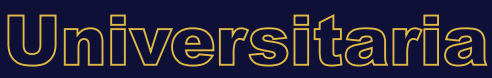

\section{El cuidado de las parteras nahuas prehispánicas de México en las crónicas de fray Bernardino de Sahagún}

\section{Care provided by prehispanic Nahuas midwives in Mexico according to the Chronicles of fray Bernardino de Sahagún}

\section{O cuidado das parteiras nahuas prehispánicas do México nas crónicas do fray Bernardino de Sahagún}

\author{
J. Badillo-Zúñigaa ${ }^{\mathrm{a}, 2}{ }^{*}$, J. Alarcón-Hernández ${ }^{\mathrm{b3}}$ \\ ORCID \\ a $0000-0001-9164-4933$ \\ b $0000-0002-5246-8807$ \\ ${ }^{1}$ Universidad Nacional Autónoma de México, Escuela Nacional de Enfermería y Obstetricia, \\ Ciudad de México, México \\ ${ }^{2}$ Instituto Nacional de Rehabilitación Luis Guillermo Ibarra Ibarra, Ciudad de México, México \\ ${ }^{3}$ Secretaría de Salud del Estado de Morelos, Jurisdicción Sanitaria III, Centro de Salud Rural \\ Tlalnepantla, Consulta Externa, Tlalnepantla, Morelos, México
}

Recibido: 28 noviembre 2019

Aceptado: 26 marzo 2020

\section{RESUMEN}

Introducción: Reconstruir historias contribuye a forjar identidades sólidas. El ejercicio interdisciplinario desde la metodología histórica, permite vincular la disciplina de enfermería con las prácticas tradicionales de la partería del México Antiguo enfocada en la actividad del cuidado de la mujer embarazada. 
Objetivo: Interpretar el cuidado de las parteras nahuas prehispánicas de México en las crónicas de fray Bernardino de Sahagún.

Desarrollo: Se analiza el papel de las parteras nahuas prehispánicas tomando como fuente primaria el facsímil del Códice Florentino o Historia General de las Cosas de Nueva España de fray Bernardino de Sahagún, disponible en la Biblioteca Central de la Universidad Nacional Autónoma de México (UNAM), en conjunto con fuentes secundarias de investigadores especialistas de la cultura náhuatl. Con base en la hermenéutica para la historiografía de la Colonia, la investigación se organiza en dos dimensiones, de lo general a lo particular. Mientras que la primera muestra los aspectos generales, geográficos, la cosmogonía y cosmovisión de la población estudiada; la segunda corresponde a las características sociales, culturales, políticas y fenomenológicas como son símbolos, cualidades, divinidades, además de significaciones en torno a la partera.

Conclusiones: El estudio de la historicidad de la partería devela prácticas tradicionales permeadas de la cosmovisión mesoamericana, de las cuales subyace un cuidado multidimensional que ve a la mujer como un reflejo del cosmos, la tierra y el origen de lo sagrado. Asimismo, desde la cosmovisión de la partera se identifica un ejercicio de prácticas tradicionales, de las cuales subyacen premisas clasificadas como supuestos epistemológicos a partir de la acción.

Palabras clave: Cuidado de la mujer embarazada; parteras nahuas prehispánicas de México; fray Bernardino de Sahagún; México.

\section{ABSTRACT}

Introduction: Reconstructing histories contributes to consolidate solid identities. Therefore, interdisciplinary actions, from the historic perspective, allow linking the discipline of nursing to the traditional midwifery practices which were focused on the care of pregnant women during the times of ancient Mexico.

Objective: To interpret the way of caring of prehispanic Nahuas midwifes in Mexico based on the chronicles of fray Bernardino de Sahagún.

Development: The role of prehispanic Nahuas midwives is analyzed through the consultation of a facsimile of the fray Bernardino de Sahagún Florentine Codex or General History of the Things of New Spain, available at the Biblioteca Central de la Universidad Nacional Autónoma de México (UNAM), as the main source, along with other secondary sources from diverse researchers of the Nahuatl culture. Based on the hermeneutics of the historiography of the colonial period, the research is organized in two dimensions: the general and the particular. While the first addresses the overall aspects related to the geography, cosmogony, and worldview of the studied population, the second focuses on the related social, cultural, political, and phenomenological characteristics, including the symbols, divinities, and meanings around midwifery.

Conclusions: The study of this midwifery unveils traditional practices which suggest the prevalence of multidimensional care that addresses women as reflections of the universe, the land, and the sacred origin, all in agreement with the epistemological postures of these cultures.

Keywords: Pregnant women care; mexican pre hispanic nahuas midwives; fray Bernardino de Sahagún; Mexico. 


\section{RESUMO}

Introdução: Reconstruir histórias contribui a forjar identidades sólidas. O trabalho interdisciplinar desde a metodologia histórica, permite ligar a disciplina de enfermagem com as práticas tradicionais da parteria do México Antigo focada na atividade do cuidado da mulher grávida.

Objetivo: Interpretar o cuidado das parteiras nahuas prehispánicas do México nas crónicas do fray Bernardino de Sahagún.

Desenvolvimento: Analisa-se o papel das parteiras nahuas prehispánicas tomando como fonte primária o fac-símile do Códice Florentino ou História Geral das Coisas da Nova Espanha de fray Bernardino de Sahagún, disponível na Biblioteca Central de la Universidad Nacional Autónoma de México (UNAM), em conjunto com fontes secundárias de pesquisadores especialistas da cultura náhuatl. Com base na hermenêutica para a historiografia da Colônia, a pesquisa organiza-se em duas dimensões, do geral para o particular. Enquanto a primeira mostra os aspectos gerais, geográficos, a cosmogonia e cosmovisão da população estudada, a segunda corresponde às caraterísticas sociais, culturais, políticas e fenomenológicas como são: símbolos, qualidades, divindades e significações em volta à parteira.

Conclusões: O estudo da historicidade da parteria revela práticas tradicionais impregnadas da cosmovisão mesoamericana, das quais subjaz um cuidado multidimensional que vê à mulher como um reflexo do cosmos, a terra e a origem sagrada. Da mesma forma, desde a cosmovisão da parteira identifica-se um exercício de práticas tradicionais, das quais subjazem pressupostos classificados como supostos epistemológicos a partir da ação.

Palavras chave: Cuidado da mulher grávida; parteiras nahuas prehispánicas do México; fray Bernardino de Sahagún; México.

\section{INTRODUCCIÓN}

Para los autores del presente artículo, el conocimiento de las parteras ha sido una práctica ancestral, social e histórica que permitió la sobrevivencia y desarrollo de grupos humanos.

Se inicia con la definición de partería como un conjunto de prácticas que apoyan a la mujer en su proceso de dar vida a otra persona, con cuidados antes, durante y después del parto, así como los cuidados del recién nacido; aunque es posible que tal enunciado adquiera otros matices al final de la investigación.

Cuidar a la mujer embarazada generó en todas las latitudes un rol social circunscrito perfectamente y reconocido desde épocas ancestrales, de lo cual se tiene huella historiográfica en casi todas las culturas. Tales cuidadoras, en su mayoría mujeres, dieron origen a las parteras, conocidas también como madrinas, comadronas o abuelitas.

El objetivo de la investigación es interpretar el cuidado de las parteras nahuas prehispánicas de México en las crónicas de fray Bernardino de Sahagún. Elegir a los pueblos nahuas de la época prehispánica corresponde a la disponibilidad de información, pues sobre ellos se tiene mayor cantidad de registros, además es en quienes se reúne y resume la cosmovisión de los pueblos mesoamericanos que florecieron antes de la llegada de los españoles.

Los elementos fenomenológicos, místicos, históricos, inclusive epistemológicos que giran en torno a la figura de la partera y sus prácticas, han sido producto de múltiples reflexiones. 
Hay quienes distinguen la existencia de un profundo conocimiento de las parteras en el cuidado de la mujer en todos sus estados; sin embargo, existen otras opiniones que niegan dicho conocimiento y descalifican su efectividad. Ante esta cuestión y otras propias de la disciplina de Enfermería, se desprende el interés por revisar lo que se registró sobre estas mujeres mesoamericanas en una de las obras más relevantes de aquel periodo, el Códice Florentino, para posteriormente interpretar el cuidado que practicaba la partera nahua en la época prehispánica.

El estudio es histórico y se forja en tal metodología $a^{1-3}$, de ahí que se recurra al uso de fuentes secundarias de los estudiosos de la cultura náhuatl que deconstruyeron registros en interpretaciones, así como la obra de fray Bernardino de Sahagún, nuestra fuente primaria4, donde se encuentra toda la información que el fraile recabó de sus viejos informantes nahuas, fue consultada en sus dos versiones, el Códice Florentino y el documento realizado por Sahagún.

En dicho sentido, se identificaron las cualidades propias de la actividad del cuidado implícitas en las prácticas tradicionales de las parteras, lo que permitió dar una interpretación de lo que fue la partería en ese periodo y su vínculo con el actual concepto denominado cuidado. Así mismo, se recurrió a otras fuentes, de tal manera que la heurística o revisión y selección de la información se sometió a un ejercicio interpretativo bajo la hermenéutica para la historia en el México Colonial planteada por Mauricio Beuchot ${ }^{5,6}$, para la comprensión de los registros historiográficos seleccionados. Resulta relevante señalar ciertos puntos que se consideran importantes por los cuales reunir, interpretar y mostrar algunos datos históricos de una práctica tradicional como la partería, con un rol social que aún persiste en muchas comunidades del país.

Dicha práctica se presenta en toda la extensión de América Latina, donde se redimensiona en la medida en que la cosmovisión de cada cultura va otorgando a estos sujetos sociales y su oficio, valores como la confianza, así como saberes reconocidos y aceptados por el colectivo de sus comunidades. A su vez, esto conlleva a un encuentro con la enfermería (comunitaria o clínica) donde se posibilita la existencia de un choque cultural en la atención del cuidado de la mujer embarazada, lo cual debe traducirse en un proceso de comprensión con base en el conocimiento, que inicia en su historicidad y toca reconstruir a la enfermería.

Cabe destacar que la partería cumple un rol sumamente importante, se han identificado tres funciones básicas, centradas en el rol que desempeñan dentro de su comunidad. La primera de ellas está basada en la relación afectiva que la partera establece con las mujeres embarazadas, con efectos positivos tales como disminución en la ansiedad y aumento en la confianza de la parturienta. La segunda función tiene impacto importante en los costos, se origina del conocimiento de las necesidades y carencias económicas de las mujeres por la partera. La tercera función se basa en el apoyo que reciben las mujeres postparto de las parteras para las labores domésticas y el cuidado de los hijos. Estas tres funciones sumadas a la falta de otros servicios de salud institucionales hacen de las parteras tradicionales un recurso humano altamente demandado. Estudios reportan datos relevantes en México, alrededor de un 30\% de los partos son atendidos por parteras, inclusive hasta un $100 \%$ en comunidades con mayor población indígena. Acorde a las estadísticas presentadas por el Instituto Nacional de Estadística Geografía e Informática, los estados con mayor porcentaje de partos atendidos por parteras son: Chiapas (74\%), Oaxaca (56\%), Guerrero (51\%), Tabasco (42\%), Veracruz (42\%), Puebla (33\%) y San Luis Potosí (27\%)7.

En áreas rurales de alta marginalidad y difícil acceso a los servicios de salud institucionales, la práctica de la partería tradicional se mantiene vital. En las poblaciones indígenas las parteras suelen ser el único recurso de salud para la población materno-infantil, es en esas comunidades donde 
las mujeres tienen más dificultades en el acceso de tipo geográfico, cultural y económico, a hospitales de segundo o tercer nivel para la atención durante el embarazo, el parto, así como en el postparto.

En efecto, mostrar los datos históricos de una práctica tradicional tan arraigada en varias comunidades del país, sugiere a su vez el análisis de una visión que merece ser indagada y contextualizada, inclusive, como fuente de conocimiento desde su historicidad. Aunque en los registros encontremos desde virtudes hasta graves descalificaciones; lo cierto es que en la actualidad la transversalidad de la cultura nos coloca en una posición de indagación histórica, interdisciplinaria, como parte de un ejercicio profesional obligatorio para las necesidades y retos de su presente.

Por este motivo, la posibilidad de reconstruir la historia de una actividad que prevalece hasta el presente, contiene su valor en lo que de ello puede ser utilizado para reflexionar, comprender, difundiry estimar una de las circunstancias humanas más sensibles, vulnerables e inclusive místicas, como lo es el nacimiento. A su vez, la posición de la mujer en tal evento, el rol de la partera, la forma en cómo interactúan con la mujer que va a parir, el esposo, las abuelas, entre otros integrantes que se involucran según la región; sus tradiciones y cosmovisión, donde la enfermería obstétrica debe sujetar su ejercicio profesional con el análisis histórico, bajo una consciencia crítica de compromiso propio de un sujeto trascendental.

La información interpretada en el presente artículo se destaca en tres aspectos: primero, la importancia de realizar investigación interdisciplinaria; segundo, el conocimiento de la partería tradicional prehispánica debe verse como una fuente de conocimientos que conlleve al rescate de los saberes antiguos; tercero, la historia genera un proceso dialéctico y discursivo entre el conocimiento ancestral de las prácticas tradicionales como en la enfermería obstétrica profesional del siglo XXI.

\section{DESARROLLO}

\section{Los nahuas prehispánicos}

Durante el periodo posclásico se dio una especie de reorganización de los primeros linajes nahuas. Con la llegada de tribus del norte y sus precarias formas de vida, entre ellos los mexicas, los nahuas lograron crear un dinamismo con estos migrantes que los ayudó a desarrollarse. Miguel León Portilla menciona que de entre estos pueblos de idioma náhuatl se encontraban: Cholula, Xochicalco y después Tula; de este último conocemos su influencia tanto filosófica como religiosa con el nombre de la Toltecayotl o toltequidad ${ }^{9}$, que permeó fuertemente el pensamiento de los pueblos que se asentaron después en el Anáhuac ${ }^{10,11}$.

De acuerdo con Portilla, en el caso de la vinculación e influencia del pueblo mexica o nahua que se estudia, la conformación de su religión y sociedad que floreció y dominó una gran parte del territorio mexicano, se configuró gracias a la unificación de los conocimientos de las sociedades que se desarrollaron previo a su llegada ${ }^{10}$. A su vez, los nahuas retomaron e hicieron suya aquella filosofía a la que dieron sus propias variaciones, como lo es el nacimiento de un nuevo Dios llamado Huitzilopochtli.

Registros de fuentes primarias mencionan que estos mexicas ${ }^{11}$, tenochcas o nahuas, llegaron del norte de lo que hoy es México, en aquella peregrinación de los pueblos nacidos en el mítico Chicomóztoc, historia o leyenda plasmada en el Códice Tira de la Peregrinación ${ }^{12,13}$, el cual se encuentra en el Museo Nacional de Antropología e Historia ubicado en la Ciudad de México. Cabe señalar que en la pintura-escritura de la Tira de la Peregrinación, se observa una mujer gobernante representando a uno de los pueblos que salieron del misterioso lugar de las siete cuevas, lo cual refleja que las mujeres eran sujetos sociales que se encontraban en condiciones de igualdad 
frente a los hombres, y que como veremos en el desarrollo de este trabajo, las parteras también ocuparon una alta jerarquía en aquella antigua sociedad.

Alfonso Caso relata con una personal poética la leyenda de El águila y el nopal como la fundación de la ciudad del sol en medio de la luna ${ }^{14,15}$. Otros estudiosos comentan que durante la fundación de la ciudad de los mexicas se dio un evento que se destaca como importante por su carga de significados, es decir, el sacrificio del Colhuaque Chichilquáhuitl del que se ofrenda su corazón, donde interpretan que las tunas del nopal que devora el águila son el florecimiento del corazón del guerrero, fundándose así México-Tenochtitlan (El pueblo del Sol) en el año de 1325. Al respecto, Johansson K. menciona que: del corazón sacrificado de Cópil brotará el tunal tenochtli, axis mundi del futuro asentamiento mexica ${ }^{16}$.

Otras fuentes secundarias mencionan la especificidad de la región geográfica donde los nahuas se asentaron, en otras palabras, el altiplano central de México. López Austin la divide en dos: la primera es el valle de México, el cual contenía en aquella época un conjunto de vasos pantanosos que se inundaban en tiempo de lluvias para formar un solo lago, estos llamados vasos de agua eran los de Xaltocan y Zumpango al norte, el de Tetzcoco al centro, los de Chalco y Xochimilco al sur. La segunda región es la de los valles de Puebla y Tlaxcala, separados de Tenochtitlán y los otros pueblos nahuas por la Sierra Nevada, en esta región destacaron las poblaciones de Cholollan, Tlaxcallan, Huexotzinco ${ }^{15,17}$, Tlaxcala, Cholula y Puebla ${ }^{18,19}$. Aunado a la ubicación geográfica, además de aquellas semejanzas de lo que creían de las cosas y la naturaleza, los nahuas se expresan siempre por el camino de la poesía: In Xochitl In Cuicatl (flor y canto ${ }^{19}$ ).

Con respecto a su forma de interactuar e interpretar la vida, Portilla afirma que Alfonso Caso descubrió la clave del pensamiento nahua, es decir, que el hombre, la muerte y todos los fenómenos relacionados con la naturaleza existen a partir de la idea de: el hombre como colaborador de los dioses $^{10,19}$, es decir la relación entre humanos y divinidades es estrecha, parece no haber ninguna separación de tales realidades.

A partir de la pequeña exposición de la cosmovisión de los nahuas es posible decir que las parteras como sujetos sociales que cuidan el proceso de la mujer embarazada, tienen saberes específicos con prácticas tradicionales como acciones propias de un conocimiento elaborado y estructurado; principalmente, proveen un cuidado con alcances humanistas trascendentales a partir del pensamiento místico que lleva a cuidar de una forma que va más allá del cuidado del cuerpo. Esto parece emerger de la creencia del origen divino del ser mujer, representar la vida y la tierra, donde todo es sagrado.

\section{Interpretaciones sobre el ser partera}

Afortunadamente aún existen códices prehispánicos ${ }^{13} \mathrm{y}$ crónicas coloniales que otorgan información sobre las parteras de los nahuas prehispánicos, entre ellos se encuentra el Códice Mendoza, donde se puede observar a la partera realizando actividades de su oficio. Otro importante legado como fuente primaria es el Códice Florentino ${ }^{20}$, también conocido como Historia de las Cosas de Nueva España, manuscrito en el cual se sustenta la presente investigación.

En dicho documento se describen varias prácticas que realizaba la partera, por ejemplo, organizaba las actividades de los familiares de la mujer preñada y recitaba oraciones a varias divinidades (Chalchiutlicue, Yoalticitl, Omecihuatl, Teteuinan, Tonatiuh, Tlatecuhtli) durante el baño del recién nacido, la siembra del nombre, así como discursos para la buenaventura de la mujer embarazada, dirigidos a los familiares, recién nacido, inclusive palabras especiales cuando la madre 
moría en el parto, dando a su vez los cuidados del cuerpo. Por ello, en dicho códice se encuentran pláticas de adiestramiento de los compromisos y cuidados que se debían tener y que la partera tenía encomendado enseñar.

Si bien algunos registros mencionan el título de Ticitl como nombre en general de las personas que realizaban actividades para el cuidado y cura de la salud-enfermedad en su especificidad etimológica, es decir de origen y significado, el término en náhuatl para denominar a la partera es el vocablo: Temixihuitiani ${ }^{21}$. Dicha palabra contiene los diferentes ángulos del pensamiento nahua, la significación de la realidad excelsa y mística, que vinculadas a un fenómeno que describió León Portilla acerca de la maternidad en los pueblos nahuas, se relaciona con la representación del lazo inquebrantable de la liga de la mujer con el mundo sagrado, $0^{9,0,19,22}$. Por consiguiente, la partería se vincula en su totalidad con una actividad sagrada sujeta a diversos lazos con la tierra, la vida, las divinidades y el don, punto clave reiterado por Alfonso Caso, Miguel León Portilla, Aguirre Beltrán, entre otros estudiosos de las fuentes primarias.

Es entonces que en la partera se puede observar una de las características más relevantes, un ser humano como colaborador de las Divinidades ${ }^{14,19,21,22}$. Una deidad con la que está directamente relacionada la partera es Tlazohtéotl o Tlazoltéotl, es la divinidad de la embarazada y de las parturientas; además de que es quien propicia los buenos partos, protege a las Cihuateteo, es protectora de las parteras y del temazcal, llamada también como la abuela del temazcal, la anciana madre de la tierra ${ }^{23}$.

En consecuencia, las parteras eran consideradas como sujetos sociales dotadas de virtudes espirituales para llevar a cabo el cuidado de la mujer embarazada. Articulaban un fenómeno que daba a su ejercicio, a la mujer, al recién nacido y a la vida, una existencia de dignificaciones humanísticas, sagradas, tangibles e intangibles, implícitas en el ejercicio vivo de los cuidados que reúne la partería, por lo cual puede decirse que el eje del cuidado de las temixihuatiani es el cuidado de la mujer y el recién nacido en un sentido sagrado.

A fin de reafirmar que la mujer tiene fuertes y especiales relaciones con la actividad de cuidar como una condición humana sagrada y cultural, los ámbitos en los que ha desarrollado un rol social bien definido con prácticas específicas de cuidado de la vida; se puede recurrir a la historia realizada por Alfredo López Austin, donde menciona que también existieron diferencias entre las parteras de otros lugares del mundo, inclusive de una región cercana a otra y esto fue debido a la tradición²4.

Si bien las interpretaciones de los estudiosos citados nos otorgan un marco de referencia sobre las parteras prehispánicas, el bosquejo que se presenta desde la mirada de la enfermería coadyuva a un ejercicio discursivo, reflexivo y dialéctico entre el pasado de una partería tradicional de tono humanista, frente a una enfermería obstétrica altamente especializada.

\section{La mirada de humanismo contradictoria de fray Bernardino de Sahagún}

Sin duda, uno de los legados historiográficos de los frailes misioneros que llegaron al México precolombino a partir de $1524^{25}$ y dejó registros de quiénes eran los nahuas, fue la obra escrita por el fraile Bernardino de Sahagún, de la orden franciscana. Sahagún recopiló su información bajo tres tipos de fuentes: la información proporcionada por los ancianos principales en Tepepulco y Tlatelolco; los códices con su escritura pictográfica; y los textos que habían compilado fray Andrés de Olmos y fray Toribio de Benavente Motolinia.

La Historia General de las Cosas de Nueva España es también conocida como Códice Florentino, escrito en náhuatl y español, fue una tarea que emprendió Sahagún con el fin de conocer mejor a 
los indígenas para realizar la empresa encomendada por la corona española, la evangelización, que también es parte de la colonización, en este caso, la colonización en el plano espiritual.

Es importante determinar la posición filosófica con la que fue escrita la fuente primaria, eje del presente artículo; conocer los antecedentes de la corriente de pensamiento ayuda a entender ciertas posturas que se reflejan en la interpretación del fraile, entre otros elementos necesarios para el análisis de las crónicas coloniales. Recordemos que en la Europa del Siglo XVI se estaba llevando a cabo una revolución de pensamiento, arte, ciencia y cultura, conocida como el Renacimiento, de la cual surgió el humanismo como movimiento que proliferó en Italia con la intención de encumbrar al hombre, retomar a los clásicos griegos y sus principios filosóficos. Tal contexto filosófico conformó la postura del pensamiento de aquellos frailes que llegaron a la Nueva España, posterior a sus estudios en universidades como la Antigua Universidad de Salamanca.

Con base en lo anterior, se afirma que la postura ideológica de fray Bernardino de Sahagún es la de un humanismo contradictorio, es decir, un humanismo entre lo dogmático de la Iglesia y el pensamiento republicano de Platón aprendido en la Universidad de Salamanca, lo que se piensa, influyó en el interés y forma al realizar su gran obra ${ }^{26,27}$.

\section{La partera en los registros de fray Bernardino de Sahagún}

En el proemio de la obra Historia General de las cosas de la Nueva España ${ }^{28}$, se relaciona a la partería con dimensiones místicas y sagradas, ejemplo de ello lo encontramos en el libro quinto que se refiere a los agüeros, donde se mencionan elementos como el cordón umbilical, el temazcalli (baño ritual), la preñada, la casa de la mujer preñada; mismos que están involucrados en augurios y amuletos con los que de alguna manera, la partera tiene contacto.

Los cuidados de la partera iniciaban en el momento en que los familiares de la mujer embarazada se reunían para determinar cuando debía empezar a intervenir, la elegían para encargarse de atender el proceso de embarazo, parto y al recién nacido. La solicitud a la partera para cuidar el embarazo y parto, se realizaba en medio de ritualísticos poemas donde se manifestaba que tenía el conocimiento para cuidar a la mujer, mencionándole que deseaban salud a vuestro corazón y a vuestro cuerpo, con todo contento; no hay otra persona más hábil... ${ }^{28}$. De esta forma le expresaban su reconocimiento como sujeto de sabiduría, por ende, obtenía un compromiso social y divino. Recordemos que el primer acuerdo que tenía la partera era la de ser una colaboradora de las divinidades. Si bien al aceptar la petición de los familiares adquiría obligaciones con la mujer preñada, el esposo, la familia y el futuro recién nacido; dicho convenio también le otorgaba un estatus de jerarquía frente a ese grupo, así como la sociedad.

De las diligencias que tenía a su cargo la partera era otorgar pláticas a la mujer embarazada, preparar el baño o temazcalli, del cual debemos recordar existían divinidades regidoras con las que debía mantenerse en vinculación. Una vez iniciado el trabajo de parto, realizaba baños, daba de beber yerbas e incluso cocinaba animales específicos para mejorar y agilizar el trabajo del parto. Al mismo tiempo, la partera no perdía su sentido ritualista, sino que mantenía los rezos, aumentaba sus cuidados y prácticas para favorecer el nacimiento. Por ejemplo, si advertía que el producto venía atravesado, daba masajes para cambiar la posición y favorecer la expulsión, si consideraba necesario volver a dar baño de yerbas a la mujer, volvía a realizar dicha práctica.

Los actos importantes eran los recitales que se daban durante el trabajo de parto, así como en el nacimiento, dirigidos de la partera a la parturienta; de la partera a las abuelas y madres de los esposos y viceversa; de la partera al esposo, todos estos se caracterizaban por tener un alto valor estético 
como ritualístico, poético y sagrado. En aquel momento, la partera mencionaba la importancia del cuidado de la mujer recién parida a través de estas palabras: ...tengáis mucho cuidado con ella; mirad que no haya negligencia, mirad mucho por ella, tened mucho cuidado de ella...28.

En dado caso de que el nacimiento no llegara al término y el producto muriera, la partera retiraba el producto de la cavidad uterina para salvar la vida de la madre; pero si la familia creía que la incapacidad de parir era un acto de debilidad, evitaban que la partera realizara esta acción, por lo tanto, la mujer moría. Los cuidados al cuerpo de la mujer muerta los otorgaba la partera, los cuales consistían en bañar, cambiar ropas nuevas, finas, peinar y continuar con los rezos. A las mujeres muertas en el parto se les llama Cihuapipiltin, por la condición de su muerte eran equiparadas a un guerrero muerto en la batalla, además de que se creía que se transformaban en divinidades celestes que acompañaban al sol en su tránsito por el cosmos. Hoy en día se piensa que tal cosmovisión se relacionaba con grandes semejanzas con otros casos, prácticamente iguales por todo Mesoamérica ${ }^{29}$.

En el caso de consumarse el nacimiento, la partera recibía al recién nacido en medio de rezos y advertía acerca de la incertidumbre presente en la temporalidad de la vida. Después cortaba el cordón umbilical con un pedernal o piedra; si era un niño, enterraba el cordón en el campo de batalla; si era niña, enterraba el cordón junto al fogón de la casa. El baño del recién nacido era una práctica para limpiar el cuerpo y el corazón como representante de una energía vital, buscando dotar al recién nacido de fortaleza para ser una buena persona. Al realizar esta limpia, la partera invocaba a la divinidad de Chalchihuitlicue (la de la falda de jade) ${ }^{30}$, que se relaciona con el agua con la que se realizaba la limpieza.

Como parte de los cuidados postparto, la partera enaltecía a la madre a través de recitales por su valentía al parir. Durante este momento relataba a la mujer como el parto se concebía entre las situaciones más importantes de la vida, de origen divino y digno del don propio de la tierra, el dar vida; lo cual originaba una conexión inquebrantable de la mujer con lo sagrado del acto.

En efecto, la partera era un sujeto con una jerarquía elevada dentro de su sociedad, lo cual se aprecia en la organización de la familia durante todo el proceso del embarazo y parto, así como al recitar los designios del recién nacido, como si fuera la propia divinidad de Tlazohteotl materializada para descifrar el futuro del nuevo miembro, con lo cual su rango cobraba una dimensión de divinidad. También era encargada de realizar rituales y actividades importantes como bautizos, cada una de estas acciones nos ilustra la jerarquía social e incluso política que ocupaba la partera en la antigua sociedad prehispánica.

Cabe señalar que la partera estaba siempre presente en todas las ceremonias y ritos al respecto de la gestación, cumplía con la práctica de enseñar, proporcionar y transmitir saberes tradicionales en su papel de mujer-anciana especialista, mismos que abarcaban: educación de la pareja, embarazo, parto, puerperio y atención del recién nacido. Tomando como sustento historiográfico el discurso de Sahagún, se afirma que lo que otorga la Temixihuatiani a los recién casados en su momento a la mujer embarazada y al recién nacido son: cuidados, ya que dicho texto incurre, como otros; en el uso del término cuidado para nombrar a las actividades o prácticas tradicionales que realizaba la partera.

Tocante al cuidado de la ticitl, este nombre fue usado para todos aquellos sujetos sociales que realizaban prácticas tradicionales para atender la salud y la enfermedad, en el caso del oficio de la partería, la ticitl, temixihuitiani, partera, especialista en partos, se le ha encomendado a través de dicha palabra, una misión más allá del simple cuidado físico. Esto último se puede vislumbrar en el 
texto de Sahagún: ...en cuyas manos, y en cuyo regazo, y en cuyas espaldas ponéis y echáis esta vuestra piedra preciosa y esta vuestra pluma rica, y también lo que tiene en su vientre ${ }^{28}$.

Para ejercer su oficio, la partera estaba sujeta a ciertas responsabilidades y compromisos adquiridos al aceptar su figura. La primera responsabilidad era ser colaboradora de las divinidades; posteriormente los encargos se extendían hacia la mujer preñada, el esposo, la familia, la sociedad y el próximo hijo en gestación. Durante el parto, una de las actividades más significativas que realizaba consistía en dar fortaleza emocional y espiritual desde su propia noción de ser partera, además de fungir como intermediaria de una fuerza superior para cuidar el cuerpo. El acto de cuidar implicaba un compromiso social bajo una perspectiva ritualista con acompañamiento, educación y apoyo; por lo que estas prácticas se determinaban como producto de una concepción humanista y espiritual.

Las prácticas tradicionales que realizaba la partera se encuentran bajo un concepto eje, el cuidado de la mujer embarazada, así como todas aquellas actividades educativas que pronunciaba en sus rezos y recitales.

Es importante tener en cuenta que la presencia de registros de las acciones y contexto de las parteras en una sociedad que se construyó sobre un marco cultural, colectivo y espiritual en torno al embarazo y nacimiento, indica que la práctica del cuidado estaba implícita en el estilo de vida de los nahuas prehispánicos. Quizá por ello, Sahagún junto con sus informantes nahuas, utilizaron el concepto cuidado como un término adecuado para la práctica tradicional que realizaban las Temixihuitiani.

En la tabla 1 se presentan los libros y capítulos de la obra de Sahagún que vinculan o hacen referencia a las parteras.

\section{CONCLUSIONES}

Las prácticas tradicionales de las parteras descritas en la obra de Sahagún, se suscriben dentro de una esfera semántica propia de lo que actualmente, para la enfermería, entendemos como cuidado de la mujer gestante; a través de la disección del texto, observamos que ofrecían cuidados específicos para la embarazada. La figura de la partera trasciende como un sujeto social e histórico que practicó lo que podemos llamar cuidado multidimensional, ya que contiene atención implícita de las dimensiones metafísica, espiritual, corporal, moral, humanista, siempre desde un sentido ritualista.

Enla partería convergen elementos de tipo místico-religioso, socialy cultural,con representaciones activas de un conjunto de actos que apoyan a la mujer en su proceso de dar vida, con cuidados en su mayoría otorgados por mujeres, durante la preconcepción, gestación, parto, puerperio y atención neonatal. Esto se piensa y analiza a partir de la existencia de un contenido epistemológico centrado en la acción; para el caso de la partería tradicional, está dotado de una postura sagrada.

Así, el ejercicio de la partería prehispánica tiene una dimensión enaltecida. Durante este proceso se configuran cualidades y comienza a gestarse una forma de actuar que les permite interpretar la naturaleza de la vida entre rituales, símbolos y valores humanos en medio de cantos y flores, además de que se determina una práctica tradicional de gran arraigo, fortaleza, así como desarrollo de una estructura social.

Finalmente, el legado que dejaron las parteras náhuatl se ha perpetuado hasta la actualidad en la partería tradicional. 


\section{Tabla 1. Clasificación de registros en la obra de Sahagún donde se menciona a la partera y sus cuidados ${ }^{28}$}

Libro Quinto. De los agüeros y pronósticos, que los naturales tomaban de algunas aves, animales y sabandijas para adivinar las cosas futuras.

En los capítulos:

\begin{tabular}{ll} 
IX. & Del ombligo \\
\hline $\mathbf{X}$. & De la preñada \\
\hline $\mathbf{X I .}$ & De la casa de la recién parida \\
\hline $\mathbf{X I X .}$ & De la mujer preñada \\
\hline $\mathbf{X X X V I .}$ & Del baño o temazcalli
\end{tabular}

xxxvı. Del baño o temazcalli

Libro Sexto. De la retórica, filosofía moral y teología de la gente mexicana, donde hay cosas muy curiosas, tocantes a los primores de su lengua, cosas muy delicadas tocantes a las virtudes morales.

En los capítulos:

XXVI. En que se pone lo que los padres de los casados hacían cuando ya la preñada estaba en el séptimo u octavo mes; y es que los padres y parientes de los casados se juntaban en casa de los padres de ella y comían y bebían, lo cual, acabado, un viejo de la parte del marido hacía un parlamento para que se buscase una partera instruida en su oficio para que partease a la preñada.

XXVII. De cómo una matrona parienta del mozo hablaba a la partera, para que se encargase del parto de la preñada; y como la partera responde, aceptando el ruego, y de los avisos que da a la preñada para que su parto no sea dificultoso; donde se ponen muchas cosas apetitosas de leer y de saber y muy buen lenguaje mujeril y muy delicadas metáforas.

XXVIII. De las diligencias que hacía la partera, llegada la hora del parto, para que la preñada pariese sin pena, y de los remedios que le aplicaba si tenía mal parto, donde hay cosas bien gustosas de leer.

xxıx. De cómo las mujeres que morían de parto las canonizaban por diosas... ceremonias que se hacían, cuando la primera vez la partera ponía a la criatura (en la cuna) que era acabándola de bautizar, y de las palabras que entonces decía.

xxx. De cómo la partera hablaba al niño naciendo, y las palabras que lo dice de halago, y de ternura y amor, donde se ponen muy claras las palabras que la ventura o buena fortuna con que cada uno nace, antes del principio del mundo, le está por los dioses asignada o concedida, y la partera gorjeando con la criatura pregúntale qué suerte de ventura le ha cabido.

xxxı. De lo que la partera decía al niño cuando le cortaba el ombligo, que eran todas las fatigas y trabajos que había de padecer.

XXXII. De cómo la partera acabando de hacer lo arriba dicho, luego lavaba a la criatura, y de la manera que hacían aquel lavatorio, y lo que la partera rezaba mientras que lavaba a la criatura: eran ciertas oraciones enderezadas a la diosa del agua que se llama Chalchihuitlicue.

XXXIII. Del razonamiento que hacía la partera a la recién parida, y de las gracias que los parientes de la parida le hacían a la partera por su buen trabajo, y de lo que la partera responde, donde hay muy esmerado lenguaje, en especial en la respuesta de la partera.

xxxVII. Del bautismo de la criatura, y de todas las ceremonias.

xxxVIII. Del bautismo de las niñas, en cuanto toca algunas particularidades.

\section{RESPONSABILIDADES ÉTICAS}

Protección de personas y animales. No procede, ya que en esta investigación se trabajó únicamente con documentos.

Conflicto de intereses. Los autores declaran no tener conflicto de intereses.

Financiamiento. Ninguno. 


\section{REFERENCIAS}

1. Pereyra-Boldrini C, Villoro-Toranzo L, González y González L, Joaquín-Blanco J, Florescano-Mayet EF, Córdova A, et al. Historia ¿Para qué? México: Siglo XXI Editores; 1980.

2. Brom-Offenbacher J. Para comprender la historia. México: Grijalbo; 2014.

3. Villoro-Toranzo L. El sentido de la historia. En: Pereyra-Boldrini C, Villoro-Toranzo L, González y González L, Joaquín-Blanco J, Florescano-Mayet EF, Córdova A, et al. Historia ¿Para qué? México: Siglo XXI Editores; 1980. p. 33-52.

4. León-Portilla M. Futuros del pasado. En: Navarrete-Linares F, de la Fuente B, Broda J, JohanssonKeraudren P. El historiador frente a la historia. El tiempo en Mesoamérica. Ciudad de México: Universidad Nacional Autónoma de México, Instituto de Investigaciones Históricas; 2004. p. 27.

5. Beuchot M. Historia de la filosofía en el México colonial. Barcelona: Herder; 2019.

6. Beuchot M. Tratado de hermenéutica analógica. Hacia un nuevo modelo de interpretación. $3^{\mathrm{a}}$ ed. Ciudad de México: Universidad Nacional Autónoma de México, Facultad de Filosofía y Letras. Ítaca; 2009.

7. Pelcastre B, Villegas N, De León V, Díaz A, Ortega D, Santillana M, et al. Embarazo, parto y puerperio: creencias y prácticas de parteras en San Luis Potosí, México. Rev. Esc. Enferm. USP. 2005; 39(4):37582. https://doi.org/10.1590/So080-62342005000400002

8. Laureano-Eugenio J, Villaseñor-Farías M, Mejía-Mendoza ML, Ramírez-Cordero H. Ejercicio tradicional de la partería frente a su profesionalización: estudio de caso en Jalisco, México. Rev. Fac. Nac. Salud Pública. 2016; 34(3): 275-84. http://dx.doi.org/10.17533/udea.rfnsp.v34nзao2

9. León-Portilla M. Rostro y corazón de Anáhuac. México: Secretaria de Educación Pública; 2001.

10. Soustelle J. La vida cotidiana de los aztecas en vísperas de la conquista. $17^{\mathrm{a}}$ ed. México: Fondo de Cultura Económica; 2010.

11. Johansson-Keraudren P. Tira de la peregrinación (Códice Boturini). Arqueol. mex. 2008; (E-23): 6,17-73.

12. Noguez X. Los códices nahuas del centro de México. Arqueol. mex. 2011; (109): 38-44. https://bit.ly/2XV7xVz

13. Caso A. El águila y el nopal. Estud. Cult. náhuatl. 2015; (50): 356-70. https://bit.ly/33TIfLo

14. López-Austin A. Textos de medicina náhuatl. $5^{a}$ ed. México: Universidad Nacional Autónoma de México, Instituto de Investigaciones Históricas; 2000. https://bit.ly/2F9AS8a

15. Johansson-Keraudren P. La fundación de México-Tenochtitlán. El mito y la historia. En: EcheverríaGarcía J, Johansson-Keraudren P, Rubial-García A, Toris-Guevara G, Moncada González G, Miranda Pacheco S, et al. El historiador frente a la ciudad de México perfiles de su historia. México, D.F.: Universidad Nacional Autónoma de México, Instituto de Investigaciones Históricas; 2016. p. 41-79. https://bit.ly/2XVHMVb

16. López-Austin A. Cuerpo humano e Ideología. Las concepciones de los antiguos nahuas. $2^{\mathrm{a}}$ ed. Ciudad de México: Universidad Nacional Autónoma de México, Instituto de Investigaciones Antropológicas; 2008.

17. Vela E. Introducción. Culturas prehispánicas de México. Cultura mexica: áreas culturales, regiones y zonas arqueológicas abiertas al público. Arqueol. mex. 2010; (E-34): 6-8.

https://bit.ly/2PHGxVc

18. León-Portilla M. Los Antiguos a través de sus crónicas y cantares. Ciudad de México: Fondo de Cultura Económica; 2009.

19. De Sahagún B. Historia de las cosas de Nueva España (Códice Florentino). Madrid: Fototipia de Hauser y Menet; 1905. 
20. Aguirre-Beltrán G. Medicina y magia. El proceso de aculturación en la estructura colonial. México: Fondo de Cultura Económica; 1992.

21. León-Portilla M. La filosofía náhuatl estudiada en sus fuentes. $10^{a}$ ed. México: Universidad Nacional Autónoma de México, Instituto de Investigaciones Históricas; 2006. https://bit.ly/2DJ7OnC

22. Trejo S. Xochiquétzal y Tlazoltéotl: diosas mexicas del amor y la sexualidad. Arqueol. mex. 2007; (87): 18-25. https://bit.ly/33O-OMX5

23. López-Austin A. Un día en la vida de una partera mexicana. México: Jaca Book-CONACULTA; 1999.

24. Torchia-Estrada JC. Filosofía y colonización en Hispanoamérica. México: Universidad Nacional Autónoma de México, Instituto de Investigaciones Filosóficas; 2009.

25. Iraburu JM. Evangelización de América y México. Los franciscanos en Nueva España. Navarra, España: InfoCatólica; 2018. https://bit.ly/30RrJcS

26. Ramírez-González CI. Grupos de poder clerical en las universidades hispánicas I: Los casos de Salamanca y México durante el siglo XVI. [Tesis]. Salamanca, España: Universidad de Salamanca, Centro de Estudios sobre la Universidad; 1998.

27. De Sahagún B. Historia general de las cosas de Nueva España. 11ª ed. México: Porrúa; 2006.

28. Kirchhoff P. Mesoamérica, sus límites geográficos, composición étnica y caracteres culturales. En: Suplemento de la revista Tlatoani México. Escuela Nacional de Antropología e Historia, Sociedad de Alumnos; 1960.

29. Caso A. El pueblo del sol. México: Fondo de Cultura Económica; 2009. 